\title{
CORRIGENDUM
}

\section{Environmental enrichment rescues female-specific hyperactivity of the hypothalamic-pituitary-adrenal axis in a model of Huntington's disease}

X Du, L Leang, T Mustafa, T Renoir, TY Pang and AJ Hannan

Translational Psychiatry (2012) 2, e144; doi:10.1038/tp.2012.71; published online 24 July 2012

Correction to: Translational Psychiatry (2012) 2, e133; doi:10.1038/tp.2012.58; published online 3 July 2012
Following the online publication of this article, the authors noted an error on page 2: EIA should be the acronym for Enzyme Immunoassay, not 'Environmental Impact Assessment.' 